\title{
Conflicto y violencia en el México posrevolucionario: de Tlatelolco a Ayotzinapa
}

Recibido: 03/08/2020 | Revisado: 10/09/2020 | Aceptado: 12/12/2020

DOI: 10.17230/co-herencia.18.34.9

\section{Teresa Santiago Oropeza*}

santiagoropeza06@gmail.com

Resumen En este texto se aborda la cuestión del tipo de violencia que llevó a la matanza de Tlatelolco, en 1968, y a la desaparición de los estudiantes de Ayotzinapa en la llamada "noche de Iguala", 46 años después. El primero fue el suceso más relevante después de la Revolución mexicana; el segundo, desnudó la colusión de un Estado corrupto con el crimen organizado. Sin duda, en ambos acontecimientos hay una violencia estructural e institucional atribuible al Estado. No obstante, es necesario ir más allá para señalar las particularidades de cada uno y la manera como se vinculan, a pesar de las décadas que los separan.

\section{Palabras clave:}

Violencia estructural, Estado, movimientos estudiantiles, experiencia compartida, Tlatelolco, Ayotzinapa.

\section{Conflict and Violence in Post-revolutionary Mexico: From Tlatelolco to Ayotzinapa}

\begin{abstract}
This text addresses the question of the type of violence that led to the Tlatelolco massacre in 1968 and the disappearance of the Ayotzinapa students in what became known as the "Iguala night" 46 years later. The first was the most significant event after the Mexican Revolution; the second exposed the collusion of a corrupt state with organized crime. Undoubtedly, both events involve structural and institutional violence attributable to the state. However, it is necessary to point out the specific characteristics of each event and also how they are linked despite the decades that separate them.
\end{abstract}

\section{Keywords:}

Structural violence, state, student movements, shared experience, Tlatelolco, Ayotzinapa. 
Se ha dicho, y con razón, que el movimiento estudiantil del 68 marcó la historia contemporánea de México, por ser el suceso más relevante desde la Revolución de 1910. Varios argumentos se esgrimen en favor de esta idea, siendo el más recurrente el de que la democracia hoy, si bien imperfecta, sería impensable sin la convulsión provocada al antiguo régimen, y la consecuente apertura y consolidación de derechos y libertades, que vinieron años más tarde. De acuerdo con Carlos Monsiváis: "En 1968 se inicia, con otro nombre, la comprensión de la diversidad y emerge también el concepto de ciudadanía, muy probablemente confuso, pero ya en vías de ser uno de los grandes legados del Movimiento" (2008, p. 97, el énfasis es mío).

Podría pensarse que, a más de cincuenta años de distancia, es difícil decir algo nuevo del Movimiento, pues este se ha estudiado desde prácticamente todos los ámbitos de las ciencias sociales, siendo objeto de renombrados ensayos, obras literarias ${ }^{1}$ y hasta cinematográficas. Sin embargo, la violencia que en los últimos tiempos se ha focalizado en los jóvenes que intentan abandonar su condición de marginación mediante la escuela pública obliga a volver a los eventos del 68, desde la distancia de los años transcurridos, para develar su posible continuidad en otros hechos que han marcado la historia reciente del país. Es el caso de lo acontecido en Iguala, estado de Guerrero, en septiembre de 2014, cuando desaparecieron los 43 normalistas de la escuela Raúl Isidro Burgos, de Ayotzinapa. Pensar los dos eventos más allá de una línea cronológica llevaría a preguntarse: ¿cómo pudo ocurrir un nuevo ataque a estudiantes después del 68?, ¿el avance democrático modificó el carácter autoritario del Estado?, ¿ha cambiado México de Tlatelolco a Ayotzinapa?, ¿a quién responsabilizar?, ¿qué conexiones hay entre el movimiento del 68, compuesto por estudiantes urbanos de clase media, y los jóvenes normalistas, mayoritariamente campesinos?

Sobre la literatura en torno al 68, véase: Sorensen, D. (2007). Tlatelolco 1968: Paz and Poniatowska on Law and Violence. In: A Turbulent Decade Remembered. Stanford University Press. En cuanto a estudios especializados surgidos con motivo del 50 aniversario en 2018, véase: Draper, S. (2018). México 1968. Experimentos de la libertad, Constelaciones de la democracia. Siglo XXI; y el trabajo de Rodríguez, A. (2019). Museo del universo: Los Juegos Olímpicos y el movimiento estudiantil de 1968. El Colegio de México. 
Para avanzar en la respuesta a algunas de estas inquietudes, es importante señalar que vincular los dos sucesos no es, en absoluto, arbitrario. Recordemos que conforme al propio relato de los normalistas que sobrevivieron a lo ocurrido el 26 de septiembre de 2014, su periplo inició en Chilpancingo -y terminó en Iguala-, con el fin de conseguir autobuses para poder arribar a la Ciudad de México y asistir a las marchas del 2 de octubre. Así lo había acordado días antes la Federación de Estudiantes Campesinos Socialistas de México (FECSM), que aglutina a todas las normales rurales del país, al momento de planear su participación en las manifestaciones anuales para conmemorar el movimiento estudiantil y la matanza de Tlatelolco (Illades, 2015, p. 51).

Este dato no es mera anécdota, sino, a mi parecer, un hecho fundamental para entender el vínculo que une a los jóvenes normalistas de Ayotzinapa con los sucesos del 68. Al conmemorar la matanza del 2 de octubre, los jóvenes normalistas la traen al presente; en la consigna " 2 de octubre no se olvida", reafirman el valor de la memoria. Y es que la masacre en la Plaza de las Tres Culturas puso fin a la revuelta estudiantil del 68, pero, al mismo tiempo, la inmortalizó y la convirtió en símbolo de todas las luchas antisistémicas por venir. En el tiempo inmediato no se consiguió prácticamente ninguna de las demandas estudiantiles. Los principales líderes fueron a dar a la cárcel, en donde purgaron varios años de condena. Pero conforme ha pasado el tiempo, el 68 y la matanza del 2 de octubre se han convertido, tal vez, en la memoria más robusta de la historia contemporánea de México. En particular, para los jóvenes de las normales rurales, el 68 es un gran depósito de experiencia: "Hay tiempos históricos que sobrepasan la experiencia de individuos y generaciones [...] se trata de depósitos de experiencia que estaban disponibles antes de las generaciones contemporáneas y que seguirán actuando muy probablemente tras las generaciones contemporáneas" (Koselleck, 2001, p. 41).

En efecto, cada momento histórico es único e irrepetible; incluso, impredecible. Lo fue el movimiento estudiantil del 68, y también la persecución y desaparición de los normalistas de Ayotzinapa. Y, sin embargo, para estos últimos, el 68 fue un referente con el cual podían 
identificarse a pesar de sus diferencias. No se trata de que conocieran a fondo la historia del movimiento estudiantil: el contexto, las etapas en las que se desarrolló, las distintas marchas, el pliego petitorio, los desencuentros con el gobierno de Díaz Ordaz. Sino que, para ellos, el 68 formaba parte de una larga lucha "en contra de la opresión, de la explotación", que se remonta en el pasado hasta los héroes insurgentes. Puesto en esa perspectiva, el movimiento del 68 constituye un hito histórico, por ser una lucha llevada a cabo por estudiantes. Se convierte así en una "irrupción de lo político que se produce a partir de los cruces y las líneas de fugas respecto a las formas de identificación estática de los actores dentro de un orden autoritario que pretende fijar a cada quien su sitio" (Draper, 2018, p. 43).

Así pues, esos depósitos de experiencia no vienen dados por el conocimiento profundo de un suceso o solamente por un vínculo ideológico-político, sino por lo que un evento histórico representa o simboliza; en este caso, el derecho a disentir, el compromiso con los ideales y la lucha permanente por producir un cambio, a sabiendas de que, en ese proceso, el conflicto, la violencia y la represión son inevitables. De no ser así, resultaría inexplicable cómo podrían sentirse identificados los normalistas de Ayotzinapa con aquellos jóvenes urbanos, casi todos provenientes de familias de clase media, cuyas demandas estaban dirigidas, sobre todo, a ampliar las libertades y los cauces democráticos, demandas carentes de la radicalidad expresada en las luchas que han llevado a cabo las normales rurales.

Parto de esta premisa para abordar la cuestión del tipo de violencia que hizo posible la masacre de Tlatelolco y La noche de Iguala, 46 años después. Sin duda, en ambas hay una violencia estructural y una violencia atribuible al Estado. No obstante, es necesario ir más allá para señalar las particularidades de cada suceso.

\section{Violencia de Estado}

El 68, como se le conoce al movimiento estudiantil que en pocos meses rebasó los límites de la universidad para incorporar a otros sectores de la sociedad, fue la primera gran crisis del México posrevolucionario, en los años del "milagro" económico. 
Eran los tiempos del desarrollo estabilizador, el crecimiento de la clase media, la migración masiva del campo a la ciudad, la movilidad social propiciada por la educación pública. ${ }^{2}$ Contra lo esperado, el levantamiento estudiantil sacó a relucir las fallas de un sistema de partido hegemónico que gobernaba desde 1929. A diferencia de países cercanos - Cuba, por ejemplo-, el sistema político mexicano, hasta el 68, había tenido como pauta y característica propia la capacidad de procesar todo connato de insurrección social -proviniera de donde proviniera: los mineros, maestros, ferrocarrileros, médicos o bien grupos políticos disidentes-, concediendo prebendas o usando la vía represiva, incluido el encarcelamiento de los líderes. Es así como el movimiento emergió de un sector social inesperado, por tratarse de estudiantes urbanos de clase media, para irradiar desde su núcleo hacia otras capas sociales.

En la superficie, el México de los años sesenta se mostraba como una democracia en vías de convertirse en potencia económica. Si bien es cierto que había pobreza y desigualdad, el Estado paternalista se ocupaba de paliar algunas de las carencias más urgentes de la población, a través de instituciones de atención social, además del consabido corporativismo, herramienta funcional al partido en el poder para mantener el control de las organizaciones obreras y campesinas, así como allegar votos en cada elección. La élite política estaba convencida de que México había consolidado la paz social, fruto de la Revolución ya institucionalizada, como lo ostentan las siglas del partido dominante (PRI: Partido Revolucionario Institucional), cuyo jefe máximo era el presidente de la república. Así, a diferencia de los movimientos estudiantiles europeos y de Norteamérica, pero al igual que la Primavera de Praga, ${ }^{3}$ el 68 mexicano tuvo lugar en el contexto de un Estado de tinte autoritario, "cuyas instituciones tienen puesta en juego toda su legitimidad en la mayor o menor capacidad negociadora o 'política' del señor presidente, [así,] hasta

\footnotetext{
No obstante, la oferta educativa no era homogénea: "había un dramático desequilibrio en la oferta educativa para los jóvenes" (Rodríguez, 2019, p. 27), que se concentraba en la capital del país.

3 Sobre las revueltas estudiantiles en Europa y Estados Unidos, véase: Vinen, R. (2018). 1968, el año en que el mundo pudo cambiar. Crítica.
} 
el menor de los actos de desobediencia pueden adquirir un poder relativo muy alto y el movimiento estudiantil lo había adquirido" (Echeverría, 2010, p. 219). Probablemente el gobierno de Díaz Ordaz no calibró de forma correcta la fuerza ni el poder de la revuelta estudiantil -no, por lo menos, en un inicio- y, cuando se dio cuenta de su alcance, ya era muy tarde para experimentar con una respuesta ajena a su naturaleza autoritaria.

El centro en torno al cual giró el movimiento, que fue adquiriendo fuerza en pocas semanas, lo componían dos de las instituciones académicas más importantes del país: la Universidad Nacional Autónoma de México (UNAM) y el Instituto Politécnico Nacional ("el Poli”), fundando por el presidente Lázaro Cárdenas, en 1936. El Comité Nacional de Huelga (CNH), cuerpo organizador de la estrategia del movimiento, congregaba a líderes de ambas instituciones; en sesiones largas y acaloradas, en las cuales los estudiantes encontraron espacio para la autonomía de pensamiento y acción, se decidió una huelga indefinida y los puntos del pliego petitorio que contenía las demandas al gobierno: mayores libertades civiles y políticas, apertura democrática para partidos de oposición, libertad a presos políticos; en suma, fin de los gobiernos autoritarios. Desde la mirada del gobierno, el movimiento no lo componían estudiantes, sino jóvenes rebeldes "sin causa", que ponían en tela de juicio la legitimidad del gobierno, el orden y la paz social. Como muestra irrefutable de lo anterior, en su informe del 1 de septiembre, Díaz Ordaz dijo desconocer el pliego petitorio y negó la existencia de presos políticos, que para él "eran 'vándalos' o delincuentes [con lo cual ponía] en juego una declarada negación del movimiento estudiantil y de toda la población que lo apoya[ba]" (Draper, 2018, p. 48; el énfasis es mío).

La violencia desplegada contra los estudiantes en distintas etapas del movimiento estudiantil, de las cuales Tlatelolco aún constituye el punto más alto, se da en diferentes niveles y modalidades. En primer lugar, es la manifestación de una violencia "objetiva", que se caracteriza por reproducir las relaciones de dominación a través de la presión, la coerción velada o directa y el control (Žižek, 2008, p. 9); esto es, "un amplio sistema de violencia legal, institucionalizada, que el Estado y la sociedad confunden con la estabilidad y la paz social" 
(Montemayor, 2010, p. 183). Basta recordar la censura y autocensura de los diarios informativos durante los gobiernos del PRI, con las que se cancelaba el derecho a la libre expresión e información; se inducía un blindaje para impedir la creación y permanencia de partidos políticos de oposición y, por ende, la competencia electoral se hacía nula, con lo que, de facto, se negaba el ejercicio de derechos ciudadanos fundamentales. De hecho, la violencia de Estado se había hecho visible en la represión de la década anterior contra los "sindicatos petroleros y electricistas, telefonistas y, en menor medida, ferrocarrileros. Sectores obreros con una larga tradición de lucha" (Zermeño, 1978, p. 219).

Esa violencia sistémica adquirió su forma más visible en la violencia física de policías, granaderos y, en el caso de Tlatelolco, el ejército mismo; una violencia que asombró e indignó a la ciudadanía, pues no siempre se manifestó con tanta brutalidad; pero, cuestionada la legitimidad de las instituciones del Estado, estas se vieron forzadas a dar una respuesta frente a un callejón sin salida. Por un lado, el carácter autoritario del Estado exigía emplear los recursos de siempre, a saber, la represión, el encarcelamiento de los líderes y el silenciamiento de la prensa; pero, esta vez, la escala del conflicto rebasaba la eficacia de tales respuestas, ya conocidas y otrora exitosas. De otro lado, en el 68 el país era sede de los Juegos de la XIX Olimpiada. En este contexto, "el proyecto olímpico debía encajar en una ciudad y en una sociedad que se transformaban no sólo debido a sus dinámicas de largo plazo [...], sino también debido a las expectativas generadas por la naturaleza ecuménica de los Juegos Olímpicos" (Rodríguez, 2019, p. 71). Así, por cuanto el gobierno era supuestamente democrático y los ojos del mundo estaban puestos en él, el riesgo de ser sorprendido sin la máscara era muy grande. La fuerza que había adquirido el movimiento le exigía al gobierno, en sus instancias de control político, una respuesta que simplemente no podía ofrecer: diálogo, apertura, concesión o, al menos, negociación sobre los puntos del pliego petitorio.

Hay, sin embargo, otro factor que es necesario traer al análisis. Hemos dicho que los gobiernos priistas de mediados de siglo no se tomaban muchas consideraciones a la hora de reprimir movilizaciones 
sociales; sin embargo, ninguna de estas tuvo la extensión y la fuerza del movimiento estudiantil. Desde los primeros enfrentamientos en el mes de julio entre estudiantes de distintas escuelas y de estos con la policía, se escaló en los meses siguientes hacia verdaderas batallas campales en distintos barrios, lo que puso de manifiesto la escasa preparación y los precarios recursos de las fuerzas del orden para contener la violencia: "Enfrentar decenas o centenas de estudiantes en el corazón de la Ciudad de México exigía de una sofisticación operativa y técnica que no estaba disponible para el primer y más inmediato agente que debía enfrentar la emergencia: la policía" (Rodríguez, 2019, p. 222).

En efecto, en ese entonces México no contaba con una policía especializada para hacer frente a movilizaciones tumultuarias y dispuestas a la lucha. A diferencia de otros países de Latinoamérica, de la Revolución mexicana emanó una élite política -en buena parte conformada por militares-, pero no un cuerpo policiaco/militar de élite. Los llamados granaderos, encargados de enfrentar los disturbios, escasamente contaban con mejores recursos que la policía de "a pie"; de ahí que no consiguieran inspirar respeto alguno en los jóvenes rebeldes, lo que no significa que estos no les temieran, pues aquellos podían ser muy proclives a usar la macana y el tolete para reducirlos.

Es así como la impotencia ante un connato de rebelión en la capital del país, dentro de márgenes de acción tan estrechos, obligó a los encargados de la política y la seguridad interna ${ }^{4}$ de México a echar mano del ejército. Una clara advertencia fue la ocupación de la Ciudad Universitaria en la noche del 18 de septiembre, con el fin de apresar a los líderes del $\mathrm{CNH}$, al mismo tiempo que se endurecía la respuesta política de la presidencia. Tlatelolco fue el punto de quiebre de un gobierno arrinconado y urgido de poner fin a la revuelta, que usó la represión, a la que vino a sumarse la teoría de la conjura, según la cual la revuelta estaba auspiciada por las fuerzas oscuras del comunismo:

Luis Echevarría Álvarez, secretario de Gobierno y sucesor de Gustavo Díaz Ordaz, Marcelino García Barragán, secretario de Defensa y Luis Cueto Ramírez, jefe de la Policía de la Ciudad de México. Militares los dos últimos. 
El gobierno de Díaz Ordaz es una larga vigilia en prevención del estallido. Nunca antes la Teoría de la Conjura había dispuesto de tanto poder, de tanta gente empeñada en corroborarla. Si para los políticos "detener la embestida contra México" es la tarea del sexenio, para las fuerzas de Seguridad es su razón misma de existencia. Para la mentalidad autoritaria, el mundo se divide entre los carentes de opinión (es decir, los creyentes incondicionales de las instituciones) y los manipulados. [...] Muy probablemente, los provocadores han sido convocados y alertados meses antes y sólo esperan órdenes. Y los sucesos del 68 no requieren tanto de provocadores como de las reacciones de una policía convencida de que entre los jóvenes anida el delito de la traición (Scherer y Monsiváis, 1999, p. 63).

Nada tan útil como una teoría de la conjura para desacreditar al movimiento juvenil y recuperar, en lo posible, el control. Nada tan útil como una teoría de la conjura para justificar el uso desmedido de la violencia. Por definición, una teoría de la conjura no necesita de evidencias sólidas para sostenerse: jóvenes que gritan consignas contra el gobierno y portan la imagen del Che Guevara no pueden ser más que comunistas ganados para la causa de la Unión Soviética y de Cuba: había que salvar la patria.

Acerca del 2 de octubre en Tlatelolco, nos topamos con lo que Ariel Rodríguez Kuri llama "la saturación del campo narrativo" (2019, p. 379), es decir, una abultada cantidad de versiones ${ }^{5}$-muchas de ellas contrapuestas- de lo que ocurrió aquella tarde noche. El movimiento se encontraba en su punto más alto, no solo en cuanto a la madurez que había alcanzado en términos de organización y repercusión de sus consignas en toda la sociedad mexicana, sino también porque aparentemente había signos de apertura por parte del gobierno para

5 Están las versiones de los participantes directos, miembros del Comité de Huelga o que tenían un papel relevante en el movimiento. Entre otros, Raúl Álvarez Garín escribió La estela de Tlatelolco. Una reconstrucción histórica del movimiento estudiantil del 68 (1998). Luis González de Alba publicó la novela Los días y los años (1971); el artículo "1968: la fiesta y la tragedia" (1993), en la revista Nexos (189); y, póstumamente, Tlatelolco aquella tarde (2016). Gilberto Guevara Niebla publicó La democracia en la calle. Crónica del movimiento estudiantil mexicano (1988) y La libertad nunca se olvida. Memoria del 68 (2004). Y Miguel Eduardo Valle publicó El año de la rebelión por la democracia (2008). También están las reconstrucciones periodísticas a partir de documentos clasificados, entre las que destaca Parte de guerra, Tlatelolco 1968. Documentos del general Marcelino García Barragán. Los hechos y la historia (1999), de Julio Scherer y Carlos Monsiváis. 
entablar un diálogo que pusiera fin a la violencia callejera, lo cual era una prioridad, dada la cercanía de los Juegos Olímpicos. Sin embargo, se ha especulado que esa aparente apertura del gobierno formaba parte de una estrategia para confundir a los líderes estudiantiles. Crédulos, planearon el mitin como una concentración política y al mismo tiempo festiva. De ahí que los primeros signos de alteración del guion planeado produjeran, sobre todo, una sorpresa paralizante. A este primer momento le siguió, durante varias horas, una enorme confusión, debido a que la balacera provino de diversos puntos de la plaza, sin que, hasta hoy, haya una opinión unánime acerca de quién la inició, cuáles o quiénes eran los objetivos, y cuántos grupos militares y paramilitares participaron en la misma.

En cambio, sí hay certeza de que las distintas autoridades encargadas de enfrentar lo que se anunciaba como una concentración multitudinaria en la Plaza de las Tres Culturas actuaron cada una por su cuenta, probablemente por discrepancias y tensiones entre moderados y radicales, al interior del gobierno de Díaz Ordaz; incluso, hay razones para pensar que hubo traiciones con el fin de desacreditar al rival político. Así, ejército y grupos paramilitares -como el tristemente famoso Batallón Olimpia- actuaron siguiendo cadenas de mando con estrategias contrapuestas, con lo cual se creó una situación caótica que resultó en la muerte de decenas -acaso cientos- de personas asistentes al mitin. Paradójicamente, la noche de Tlatelolco devino en un éxito inmediato para los fines del gobierno, pues marcó el abrupto fin del movimiento estudiantil, el encarcelamiento de los líderes del $\mathrm{CNH}$ y, con ello, la llegada a los Juegos Olímpicos sin mayores tropiezos, aunque no pudo impedirse una sonora silbatina al presidente Díaz Ordaz el día de la inauguración. "Desde esa clausura, la del 2 de octubre, transitamos hacia el fenómeno de la mutación, la de los testigos, la de sectores sociales no comprometidos directamente con la protesta de los estudiantes, la de compañeros de viaje dispuestos a olvidar, al menos en lo inmediato" (Rodríguez, 2019, p. 405). 


\section{Narcoviolencia}

Un dicho popular dice que "en México no pasa nada... hasta que pasa”. Después del trágico cierre del movimiento del 68, el terremoto del 19 de septiembre de 1985 vino nuevamente a sacudir a una sociedad adormecida por los vientos de progreso de las clases medias; progreso impulsado por las políticas económicas de los gobiernos tecnocráticos neoliberales de las últimas décadas del siglo pasado.

Además de los efectos devastadores del sismo: cientos de derrumbes y muertos, sobre todo en la parte céntrica de Ciudad de México (vale recordar que, de manera casi simbólica, en Tlatelolco se derrumbó el edificio Nuevo León, una de las tantas torres que conforman ese complejo habitacional modelo de la modernidad, que nunca se acabó de fraguar), el fenómeno telúrico destapó la corrupción del sector inmobiliario, así como la falta de protocolos para actuar en un país geológicamente inestable y, más importante aún, la inoperancia del gobierno para enfrentar la crisis.

Como volvió a suceder años después, ${ }^{6}$ fue la sociedad civil, antes que sus gobernantes, la que respondió de manera organizada y solidaria para ayudar a los damnificados. Muchas familias arrojadas a la indigencia e incertidumbre constituyeron una base para que, desde ahí, surgieran organizaciones populares en pro del resarcimiento por las pérdidas ocasionadas a raíz del sismo. De tales organizaciones, más tarde, se nutrirían algunas corrientes que se incorporaron al recién creado Partido de la Revolución Democrática (PRD), una escisión izquierdista del PRI, encabezada por Cuauhtémoc Cárdenas Batel, a la que se sumó la izquierda histórica agrupada en el Partido Mexicano Socialista (PMS). La gran fisura que el movimiento estudiantil del 68 había provocado en el férreo sistema político, acostumbrado a salir siempre avante, se fue haciendo cada vez más profunda y, con ello, nuevos actores se incorporaron a la escena política. No obstante, no se logró desmontar del todo el régimen autoritario de la Revolución mexicana.

6 Casi como una broma macabra, el 19 de septiembre del año 2017 hubo un sismo de igual o mayor intensidad. Pudo tener consecuencias catastróficas; sin embargo, en esta ocasión la Ciudad de México estaba mejor preparada. Así, aunque también hubo cuantiosos derrumbes, el número de víctimas mortales fue mucho menor. 
La apertura democrática no trajo, como se hubiera esperado, la paz social. Con los gobiernos tecnocráticos se consolidó una élite económica -que se benefició de la privatización de las empresas públicas- ligada a la de los viejos empresarios alemanistas de los años cuarenta, e igualmente rapaz y eficiente para acumular riqueza. No es casualidad que Carlos Slim, beneficiado por el presidente Salinas de Gortari, quien echó a andar el Tratado de Libre Comercio con Estados Unidos y Canadá, fuera considerado, por varios años, el hombre más rico del mundo. Paradójicamente, en el marco de la apertura democrática, ganada en gran medida por las luchas populares de muchos grupos y movimientos -como el del 68-, la liberalización económica se avino muy bien con el repunte de los negocios sucios provenientes del narcotráfico, que modificó sus rutas hacia Estados Unidos, partiendo ya no de Colombia sino de territorio mexicano. Con ello, se disparó la violencia, primero acotada a ciertas zonas del país, pero imparable al discurrir el nuevo siglo.

No deja de ser desconcertante que Felipe Calderón, del derechista Partido Acción Nacional, y segundo presidente de la alternancia política, decidiera en 2006 lanzar el ejército a una guerra contra los cárteles de la droga, para entonces muy poderosos. Una guerra que, en lugar de pacificar al país, provocó la diseminación de bandas delincuenciales cada vez más violentas, dedicadas al cobro de piso (una modalidad de extorsión en la que se le exige a los dueños de negocios el pago periódico de una determinada cantidad de dinero, a cambio de no atentar contra su vida o sus propiedades. Es otra versión del cobro de vacunas en Colombia), la extorsión, el secuestro y el robo de combustible, entre otros negocios.

La economía criminal prosperó en México a la sombra del Estado, alcanzando con la globalización dimensiones sin precedentes. El narcotráfico y los demás negocios ligados a este pudieron florecer de manera exponencial porque se asentaron en la crisis secular del campo mexicano, sobre todo en la parte sur del territorio, en donde los escasos cultivos tradicionales migraron al de la amapola. A ello hay que sumar la descomposición de los aparatos de seguridad estatales en todos los niveles, causada principalmente por los bajos sueldos, resultado del precario crecimiento económico de los últimos 
treinta años. Estos factores, agudizados, constituyen el contexto en el cual tuvo lugar la desaparición de los 43 normalistas de Ayotzinapa, en la ciudad de Iguala, la noche del 26 de septiembre de 2014.

Las normales rurales, fundadas en 1926, estaban dirigidas a jóvenes campesinos para formarlos como docentes que después servirían a sus comunidades, educando a los niños que, de otra manera, no podrían tener acceso a una formación escolar. Se trató de una estrategia educativa para que los profesores no se alejaran de sus comunidades, sino que, más bien, contribuyeran a su progreso. Se buscaba sacar a la población rural de su atraso y mitigar sus diferencias educativas, económicas y culturales respecto a la población urbana. La estrategia pedagógica, se pensaba, debía acompañar a la reforma agraria resultado de la revolución de 1910.

En su larga trayectoria, estas normales rurales "han conformado una cultura magisterial particular en la que el compromiso social es un componente importante" (Civera, 2015, párr. 1). En sus comienzos, no solo debían impartir el curriculum escolar estándar, sino también desarrollar actividades culturales, deportivas y, conforme pasaron los años, también de organización política. Desde sus inicios, las normales rurales estuvieron ligadas a grupos de izquierda, de modo destacado, al Partido Comunista Mexicano; y en sus aulas se formaron importantes líderes, como, por ejemplo, Lucio Cabañas, egresado de la normal rural de Ayotzinapa, ubicada en el municipio de Tixtla, estado de Guerrero, y líder del Partido de los pobres (PDLP)?

Congregadas desde 1935 en la Federación de Estudiantes Campesinos Socialistas de México (FECSM), las normales rurales han sufrido recortes presupuestales, más aún cuando pasaron a ser administradas por los gobiernos locales. De otro lado, desde décadas atrás, con el fin de homogeneizar la educación en el país, se les ha impuesto planes de estudio extralógicos, es decir, que no se adaptan a las necesidades de las distintas comunidades en donde

7 El PDLP fue una guerrilla que actuó en la zona montañosa de Guerrero en la década de los 70. Cabañas, su líder, fue abatido por el Ejército el 2 de diciembre de 1974, en Tecpan de Galeana; en uno de los tantos capítulos ominosos de la llamada "guerra sucia". Un relato conmovedor de esa historia se encuentra en la novela Guerra en el paraíso, de Carlos Montemayor, publicada en 1997 por Seix Barral. 
están asentadas las normales, a pesar de que esta adaptación era el propósito central cuando fueron creadas (Civera, 2015). Todo ello ha llevado a que mantengan relaciones muy conflictivas con los gobiernos locales y con el gobierno federal en turno.

Además de esto, la FECSM (que agrupa las normales) siempre ha apoyado a los movimientos magisteriales y estudiantiles, como el del 68. En el Pronunciamiento por el LXXXI aniversario de la FECSM, en 2016, esta se declaró:

En contra de las reformas estructurales de corte neoliberal impulsadas por los tres niveles de gobierno [...] y los tres poderes [...] La violencia legal e ilegal del gobierno contra el movimiento estudiantil y popular del país y la criminalización de la lucha social. Del terrorismo de Estado como método de control y manipulación del movimiento estudiantil, proletario y popular. [En contraste, está a favor de] la presentación inmediata de los 43 normalistas de la normal rural IB de Ayotzinapa [...] y castigo a los culpables de los actores materiales e intelectuales de los asesinatos. Nos solidarizamos con la lucha magisterial de la CNTE [...] nos solidarizamos con todo el movimiento estudiantil que se manifieste y desarrolle en México, resaltando el apoyo total al Politécnico Nacional [...] solidaridad con las luchas campesinas, proletarias e indígenas del país [...] libertad de los presos políticos. ${ }^{8}$

Desde su postura radical, la FECSM concibe su lucha en continuidad con la revuelta estudiantil del 68; en algún sentido, estos estudiantes se sienten herederos de esos jóvenes insumisos brutalmente reprimidos. Esto no significa que haya una "vinculación orgánica" entre estos y las luchas de las normales rurales, sin embargo,

el movimiento del 68 representó un proceso de maduración política que los persuadió [a distintos grupos estudiantiles] a encontrar en la vía armada o en nuevas organizaciones la posibilidad de asegurar un cambio más justo en el país; para otros, constituyó principalmente un movimiento de masas que debía profundizarse y extenderse (Montemayor, 2010, pp. 92-94).

Las demandas de los normalistas, en los muchos conflictos que históricamente han tenido con los gobiernos estatales en turno son la expresión de una lucha prolongada y profunda por permanecer y

\footnotetext{
Pronunciamiento de la Federación de Estudiantes Campesinos Socialistas de México (FECSM), en su LXXXI aniversario. https: https://bit.ly/2PbploV.
} 
no ser ignorados, borrados, olvidados. En ocasiones se ha planteado cancelar las normales rurales por considerarlas "semillero de guerrillas", lo que tendría graves consecuencias para cientos de familias campesinas que apuestan a las mismas como el único medio de movilidad social, aparte del sicariato y el ejército. Su lucha es, pues, por la supervivencia.

Volvamos a los estudiantes de la escuela Raúl Isidro Burgos, de Ayotzinapa. Al igual que en otras normales rurales, la historia de esta escuela es la de una batalla sin tregua para conseguir mayores recursos y mantener las becas que permiten a los estudiantes ganar una plaza de maestros una vez concluida su formación, lo que los ha llevado a no pocos enfrentamientos con el gobierno local. Basta traer al recuento la muerte de dos estudiantes en 2011, en la carretera del Sol, cuando fueron atacados por las policías ministerial y federal, para obligarlos a desalojar la caseta de cobro de Palo Blanco, que mantenían retenida con el fin de ser atendidos por el gobernador Aguirre. Comparadas con la respuesta, sus peticiones no eran desmedidas: el aumento de plazas para las matrículas, la reducción a 7 de la calificación para el ingreso a la escuela y la garantía de plazas automáticas en el sistema educativo público para los egresados. Poco después del mediodía se dieron los primeros disparos con fusiles de alto poder, primero al aire y después al contingente de estudiantes que se desplazaba por la carretera que lleva a Acapulco. Estos contestaron con piedras y prendieron fuego a una bomba de gasolina que se hallaba cerca del lugar del enfrentamiento. Ese 12 de diciembre quedó grabado en la memoria de los normalistas y, de alguna manera, fue el antecedente de lo que vendría tres años después en Iguala.

En 2014, como cada año, había que planear las actividades del 2 de octubre, conmemorativo de la matanza de Tlatelolco. En la última reunión de la FECSM, la escuela de Ayotzinapa se comprometió a conseguir dinero y unos 25 autobuses para el traslado. Había que organizarse para el "boteo" (pedir dinero para la causa) y la toma de casetas. Para conseguir los autobuses, las acciones acostumbradas eran secuestrarlos con todo y chofer, y, una vez terminado el evento, regresarlos a las distintas compañías camioneras. Existía, de hecho, un acuerdo no escrito del proceso de toma y entrega (Illades, 
2015, pp. 54 y ss.), con el fin de evitar el enfrentamiento con los "ayotzinapos". En busca de más autobuses, pues no consiguieron suficientes en Chilpancingo, la tarde de ese 26 de septiembre, los alumnos de la normal Isidro Burgos se internaron en la ciudad de Iguala, otrora capital del estado. En su mayoría se trataba de jóvenes recién ingresados a la normal, que así se sometían el tradicional "bautizo" en esas lides; por ende, eran inexpertos y estaban ansiosos.

A varios años de distancia, tal vez no podamos reconstruir con toda precisión la cadena de hechos que llevó al trágico fin de esa aventura estudiantil,${ }^{10}$ que muy bien hubiera pasado sin pena ni gloria de no haberse conjuntado ciertos factores que estaban ahí, ocultos para sus víctimas: primero, un alcalde de la ciudad en connivencia con el crimen organizado, concretamente, con los llamados Guerreros Unidos, que tenían una violenta disputa por el territorio con el grupo de los Rojos: ambos cárteles estaban dedicados al trasiego de la goma de opio que se produce en la región de La Montaña. Segundo, un gobernador que era el responsable de lo sucedido en 2011 en la carretera del Sol y, no obstante, había salido impune, gracias a sus contactos en las altas esferas del poder. Tercero, una policía municipal infiltrada por los grupos criminales, que vigilaban a todo aquel que ingresara en la ciudad y que estaban más alerta esa tarde de septiembre, pues la primera dama, con nexos familiares con los Guerreros Unidos, presentaba su informe de actividades.

Pronto se corrió la voz de que jóvenes no igualenses, con el rostro cubierto con paliacates (pañuelos), habían llegado a la Central de autobuses. Desde ese momento se activaron las alarmas y se expandió el rumor de que se trataba de un grupo de los Rojos que venía a "reventar" la fiesta de la señora o bien a intentar hacerse de la codiciada plaza, lo que disparó una intensa persecución en patrullas, por varias calles y circuitos de la ciudad, para dar caza a los autobuses y sus ocupantes. En varios momentos hubo presencia de policías federales y de miembros del ejército, pero no se ha podido averiguar hasta dónde tuvieron responsabilidad en los hechos. Muchos jóvenes

\footnotetext{
Como se les llama despectivamente a los normalistas de la Normal Isidro Burgos.

10 Para un recuento puntual de lo que pudo haber sucedido esa noche, véase: Illades, E. (2015). La noche más triste. La desaparición de los 43 estudiantes de Ayotzinapa. Grijalbo.
} 
lograron correr hacia los cerros, otros se refugiaron en casas, otros fueron baleados dentro y fuera de los camiones; hasta donde se sabe, 43 fueron entregados horas más tarde a la policía de Cocula, población colindante con Iguala y cuyo cuerpo policial seguía las órdenes de Guerreros Unidos. La historia, a partir de este punto, es incierta. De acuerdo con la llamada "verdad histórica" de la Procuraduría General de la República (PGR) -actualmente Fiscalía-, la mayoría, o al menos una parte considerable de estos jóvenes, fueron asesinados, cremados en el basurero municipal y sus restos arrojados al río San Juan.

La respuesta del Estado, tanto local como federal, fue lenta y deficiente. El presidente Peña Nieto tardó más de diez días en tomar en serio lo ocurrido, a pesar de que, como en el 68, en el crimen estuvieron involucradas fuerzas del orden: policía municipal, estatal, federal y, probablemente, también el ejército, así haya sido por omisión: una prueba más del desprecio del gobierno hacia los normalistas de las escuelas rurales. Además, el fantasma de Tlatelolco, un temor que enfrentan todos los gobernantes mexicanos, acabó paralizando al gobierno, aunado a la falta de voluntad y eficiencia en la investigación; tan es así que, ante los reclamos de los familiares y la sociedad civil, se tuvo que llamar a expertos de la Comisión Interamericana de Derechos Humanos (CIDH) para que hicieran su propio estudio del caso. ${ }^{11}$ Esta negligencia fue vista como un agravio más y como parte de la misma violencia de Estado; de ahí que en las multitudinarias manifestaciones, que continuaron durante meses, como en el 68, las protestas se dirigieran al gobierno y a las fuerzas del Estado, no a los grupos criminales que habían secuestrado y desaparecido a los estudiantes.

La consigna "Fue el Estado" no pretendía señalar al propio presidente Peña Nieto como el perpetrador directo del crimen, pero en el imaginario colectivo se reactivó la idea de esa violencia que

11 El GIEI (Grupo Interdisciplinario de Expertos Independientes), cuyos integrantes fueron designados por la CIDH, trabajó durante meses recabando información y revisando los miles de documentos de la investigación de la PGR. Al final concluyó que esta contenía un enorme cúmulo de fallas, imprecisiones y omisiones, lo cual no permitía considerarla como base suficiente y confiable de la versión oficial del gobierno sobre lo ocurrido en La noche de Iguala. 
en el pasado "se desplegó en una amplia gama de regiones y sectores sociales tanto en los contextos de prevención, contención, represión, o persecución de procesos de inconformidad social" (Montemayor, 2010, p. 179); violencia que persistía muy a pesar de la transición democrática. Así mismo, la violencia de Estado se puso de manifiesto en el intento, primero, de darle una dimensión meramente local a lo acontecido el 26 de septiembre en Iguala y, más adelante, en la manera de conducir la investigación para ofrecer una "verdad histórica" que diera fin a la petición de justicia de los padres de los normalistas desaparecidos y al reclamo popular. Reclamo que ponía en entredicho los logros del "flamante" presidente: reformas estructurales en el ámbito educativo y energético, que los gobiernos anteriores habían eludido.

Así pues, en contraste con la imagen modernizadora del presidente que restauró efímeramente el priato, se actualizó la del Estado autoritario, que, como antes, recurría a las mismas estratagemas para garantizar la impunidad de personajes de las altas esferas del poder. Lo grave en este caso, a diferencia del México de los años 60, era la presencia de los grupos de crimen organizado en todos los niveles de gobierno. Al respecto, Guerrero es un caso emblemático, por lo que representa el negocio de la goma de opio que ahí se cultiva. Esto ha convertido al estado en una de las regiones más violentas del país, afectada, también, por una violencia estructural que no ha logrado mitigarse con el paso de las décadas y que se basa en la injusticia social manifestada en la exclusión, la pobreza y la falta de oportunidades.

En este sentido, las normales rurales son, en muchos casos, la única vía que tienen los hijos de campesinos para seguir estudiando. Si estas escuelas se han mantenido ha sido porque, frente a los intentos de desaparecerlas, los jóvenes han respondido violentamente; y también han sido reprimidos con mucha fuerza. Como en el 68, en la lógica del Estado autoritario, a estos estudiantes se les ve solo como guerrilleros en potencia, peligrosos por su ligazón histórica con los grupos clandestinos que décadas atrás fueron objeto de la guerra sucia. Pero, a diferencia del 68, y de los años 70, las actividades de los normalistas nunca han puesto en jaque al Estado, ni siquiera a los 
gobiernos locales; cuando mucho, han sido un recordatorio constante de las obligaciones incumplidas por el gobierno. Así, en realidad, a los normalistas no solo se les reprime por "revoltosos" e insumisos; se les reprime por el temor de que alimenten, como en el pasado, movimientos de reivindicación social. De este modo, la violencia que condujo al asesinato y desaparición de los 43 normalistas de Ayotzinapa, reconstruida a través de los relatos de los sobrevivientes y las investigaciones de los grupos independientes, ${ }^{12}$ estuvo basada en la combinación de todos estos factores.

\section{Conclusiones a prueba}

Aceptando, entonces, la tesis de la violencia de Estado, hay sin embargo diferencias importantes entre el 68 y el 2014: en Tlatelolco fueron las llamadas fuerzas del orden quienes dispararon y mataron a mansalva; fue el Estado, haciendo uso de una violencia injustificada -vistas las razones del ataque y la desproporción de los medios empleados: granaderos, ejército y grupos paramilitaresAparentemente, el objetivo era capturar a los líderes del Comité de Huelga, sin reparar en que hubiera muertes de civiles -y tal vez sin importar-, como de hecho sucedió. El Batallón Olimpia, cuyo papel fue muy relevante en la manera como se realizó el ataque, era un grupo entrenado por agentes del Estado. Según Carlos Montemayor, Tlatelolco fue un experimento policíaco-militar para enfrentar a los grupos disidentes, estrategia que más tarde se aplicaría en la guerra sucia, en particular contra la Liga 23 de septiembre. ${ }^{13}$ En contraste, en Iguala, las fuerzas estatales entregaron a los normalistas

12 A este respecto véase: Beristain, C. (2017). Los tiempos de Ayotzinapa. Akal.

13 El cierre abrupto del movimiento estudiantil del 68 convenció a muchos jóvenes de que cambiar el sistema autoritario y antidemocrático por la vía pacífica no era posible, por ello decidieron probar la vía armada. La Liga Comunista 23 de septiembre (que se fundó en 1973 y cuyo nombre alude al intento que un pequeño grupo insurrecto hizo, el 23 de septiembre de 1965, de tomar el cuartel Madera en Chihuahua), primera guerrilla conocida en el México posrevolucionario, llevó a cabo varios secuestros y asaltos para hacerse de recursos y continuar su lucha. El fallido secuestro que ocasionó la muerte del industrial Eugenio Garza Sada en 1973 desató una furiosa persecución del grupo guerrillero por parte del presidente Luis Echeverría, dando lugar a la llamada "guerra sucia”, en la cual fueron asesinados y desparecidos muchos jóvenes, sin que aún se sepa claramente cuántos. 
a grupos de crimen organizado, a cuyas órdenes se plegaron policías de distintos tipos y rangos. Si en Tlatelolco el Estado ejerció no la violencia legítima de la cual se supone tiene el monopolio, sino una violencia ilegítima y desmedida, en Iguala se trató de la renuncia del Estado a ejercer su papel de garante de la seguridad ciudadana: no solo no impidió la violencia contra los normalistas, sino que se sumó a la misma para, finalmente, ceder a los criminales el destino de los jóvenes. En suma, de Tlatelolco a Ayotzinapa puede trazarse la historia de la descomposición del Estado autoritario en peligro de convertirse en un Estado fallido, por lo menos en algunas regiones del país. Me atrevo a decir que, en este sentido, es más grave lo acontecido en Iguala con los normalistas de Ayotzinapa, sin que con esto pretenda quitar un ápice al peso moral, político e histórico de la masacre de Tlatelolco.

Concluyo con lo siguiente: si Tlatelolco ha sido un depósito de experiencia del cual han abrevado otros movimientos sociales, también es una mancha indeleble que están obligados a asumir los gobernantes de cualquier signo político en México, pues de alguna manera desautorizó al Estado, como ente que monopoliza la violencia, para ejercer de garante de la seguridad ciudadana. Esta condición indeseable para cualquier Estado que pretenda gobernar con legitimidad se agrava aún más si pensamos que los grupos de crimen organizado han adquirido un inmenso poder en lo que va del nuevo siglo, creando una situación peligrosa y perversa, tal como se pudo corroborar en lo sucedido con los normalistas de Ayotzinapa, jóvenes campesinos cuyos nombres saltaron a las noticias nacionales e internacionales solo a través de la tragedia. Visto así, lo sucedido en Iguala la noche del 26 de septiembre de 2014 nos devuelve al 2 de octubre del 68, como signo del futuro ominoso que ahora es nuestro presente $\mathbf{I}$ 


\section{Referencias}

Beristain, C. (2017). Los tiempos de Ayotzinapa. Akal.

Civera, A. (2015). Normales rurales. Historia del olvido. Nexos. https:// www.nexos.com.mx/?p=9278

Draper, S. (2018). México 1968. Experimentos de la libertad. Constelaciones de la democracia. Siglo XXI.

Echeverría, B. (2010). Modernidad y blanquitud. Era.

Illades, E. (2015). La noche más triste. La desaparición de los 43 estudiantes de Ayotzinapa. Grijalbo.

Koselleck, R. (2001). Los estratos del tiempo: estudios sobre la historia. Paidós.

Monsiváis, C. (2008). El 68: La tradición de la resistencia. Era.

Montemayor, C. (2010). La violencia de Estado en México. Antes y después de 1968. Debate.

Rodríguez, A. (2019). Museo del universo. Los Juegos Olímpicos y el movimiento estudiantil de 1968. El Colegio de México.

Scherer, J. y Monsiváis, C. (1999). Parte de guerra. Documentos del General Marcelino García Barragán. Los Hechos y la Historia. Nuevo Siglo. https://bit.ly/312U6ny

Sorensen, D. (2007). Tlatelolco 1968: Paz and Poniatowska on Law and Violence. In A Turbulent Decade Remembered. Standford University Press.

Vinen, R. (2018). 1968. El año en que el mundo pudo cambiar. Crítica.

Zermeño, S. (1978). México: una democracia utópica. El movimiento estudiantil del 68. Siglo XXI.

Žižek, S. (2008). Violence. Picador. 